\title{
Chapter 1 Nature of Science for Social Justice: Why, What and How?
}

\author{
Lena Hansson and Hagop A. Yacoubian
}

\subsection{Introduction}

"Nature of Science" (NOS) and "Social Justice" (SJ) are vivid areas in contemporary science education research. There are different conceptualizations of NOS and SJ, giving rise to divergent research agendas. NOS and SJ research areas have mostly been separate tracks, with only a few contributions across each other. The aim of this volume is to bring NOS and SJ research closer together, explore the possibilities that might arise, and start a dialogue on the characteristics of NOS for $S J$. In this chapter, we prioritize SJ as an overall aim of science education and shed light on how NOS teaching can contribute to that aim.

Both NOS and SJ research, in different ways, challenge traditional school science (e.g. Zacharia and Barton 2004) and add perspectives and new questions to science education research. NOS scholarship challenges teaching traditions where science is taught merely as facts (Leden et al. 2017), and where myths about science continue to be propagated (McComas 1998, 2020). It questions the image of science communicated as "sort[ing] things crisply into black and white, true and false, without any 'shades of grey,' partial conclusions or residual uncertainties" (Allchin

The original version of this chapter was revised: This chapter was previously published as non-open access. It has now been changed to open access under a CC BY 4.0 license. The correction to this chapter is available at https://doi.org/10.1007/978-3-030-47260-3_14

\footnotetext{
L. Hansson ( $\square)$

Department of Mathematics and Science Education, Kristianstad University,

Kristianstad, Sweden

e-mail: lena.hansson@hkr.se

H. A. Yacoubian

Department of Education, Lebanese American University, Beirut, Lebanon

e-mail: hagop.yacoubian@lau.edu.lb
} 
2003, p. 333). Thus, discussing issues about NOS in science classrooms challenges traditional science teaching not only due to incorporating new content, but also because of disputing those binary notions of true/false or black/white that are part of traditional school science, as different perspectives exist to approaching many NOS issues (see also Leden et al. 2017). SJ literature, for its part, challenges traditional school science through visions that problematize many aspects of what characterizes traditional school science. This includes how science and school science are viewed, but also includes the roles of teachers and students (see, for example, the characteristics of "Critical School Science" in Zacharia and Barton 2004). That being said, NOS and SJ research studies have mostly been on parallel research tracks.

One main focus of NOS research involves the teaching of what science is; how knowledge is developed within science; and in what ways societal, cultural and human elements are involved in these knowledge processes (e.g. Allchin 2017; Erduran and Dagher 2014; Hodson 2014; Kampourakis 2016; Lederman 2007; Matthews 2012; McComas 2020). Thus, NOS research explores how different historical, philosophical and sociological perspectives on science might be included in the teaching of science at different educational levels. However, there are different frameworks and viewpoints within NOS research that prioritize various perspectives in the science classroom. In fact, NOS research is influenced in different ways by current societal discourse, as well as by ongoing debates within the science study research fields (e.g. Rudolph 2000).

This ongoing debate is a key reason why different historical, philosophical and sociological perspectives are emphasized at various degrees by different NOS scholars. The debates have resulted in various conceptualizations and boundaries of NOS within the recommendations for NOS teaching. One example of these differences is whether only epistemic and cognitive issues should be considered part of NOS, or whether ideological and ethical issues should also be included. Such differences in NOS research mirror ongoing discussions among philosophers of science on whether science is free from contextual values (a concept used by Longino 1990), such as norms and interests being "unrelated to the cognitive aims of science" (Curd et al. 2013, p. 184). Alternatively, if such values are part of science then they may or may not be compatible with scientific objectivity. See Curd et al. (2013) for a discussion on rationality, values and objectivity in science.

Related to these ongoing debates are different views that have been raised explicitly or implicitly by science education scholars in relation to NOS research. These views range from NOS research is not doing enough to break the reproduction of positivism and/or taken-for-granted socio-cultural heritages in the teaching of science, to the view that NOS research is going too far in picturing science as contextually embedded and thereby ending up in relativism. Such discussions within science education research "tend to settle on the conflict between the apparent relativism of constructivist accounts of science on one hand and the rationalist/realist views of science on the other" (Rudolph 2000, p. 414). As editors of this book, we consider the ongoing scholarly debates on the various conceptualizations of NOS important and unavoidable due to the ongoing contentious debates within fields such as philosophy and sociology of science. The authors in this volume use different conceptualizations of NOS in their chapters, ranging from a discourse focusing on epistemic 
conceptions to ones that embody contextual values. We consider the exploration of different frameworks and perspectives on NOS as well as their consequences for teaching and learning as part of the dialogue we are aiming for.

$\mathrm{SJ}$ has been discussed in general as well as in specific relation to education. There is quite a large body of contemporary scholarship on education for SJ in general education literature. Scholars engaged in this line of research often address issues about access, power and equity in relation to education. In science education, SJ as an aim was underplayed for some time (Reiss 2003). There is a large body of science education literature on related aims such as "scientific literacy", but the latter does not necessarily incorporate a vision of SJ. Reiss (2003) argues that "the scientific literacy movement /.../ offers too narrow a vision of what science education might achieve" (Reiss 2003, p. 153). Similarly, Barton (2003) describes how the scientific literacy movements have been criticized for using a "deficit model" when discussing the needs of marginalized students. In recent years, there has been an increasing focus on SJ in science education research. Atwater et al. (2014), Barton (2003), Barton and Upadhyay (2010), and Reiss (2003) are just a few examples of scholars in this line of research.

As is the case with NOS, SJ has been conceptualized in different ways and from different perspectives. We acknowledge that there is no consensus on a definition of SJ. Instead, there are different meanings and political ideologies attached to the concept (Zajda et al. 2006). In the scholarly literature, the concept is under discussion and different conceptualizations exist and have been developed according to different traditions (see Jost and Kay (2010), Pérez-Garzón (2018) and Zajda et al. (2006) for the history of the concept). Nevertheless, "[m] ost conceptions of social justice refer to an egalitarian society that is based on the principles of equality and solidarity, that understands and values human rights, and that recognizes the dignity of every human being" (Zajda et al. 2006, p. 1). Along the same lines, Bell (2016) writes:

Social justice is both a goal and a process. The goal of social justice is full and equitable participation of people from all social identity groups in a society that is mutually shaped to meet their needs. The process of attaining the goal of social justice should also be democratic and participatory, respectful of human diversity and group differences, and inclusive and affirming of human agency and capacity for working collaboratively with others to create change.... (Bell 2016, p. 3).

As editors, our point of departure is aligned with that of Bell (2016) and Zajda et al. (2006). Thus, for the purpose of this volume, we use a rather broad conceptualization of SJ that encompasses SJ as a goal and as a process. SJ as a goal targets, for instance, social, political, economic, cultural and gender equity in science teaching and in broader society. SJ as a process involves the contributions that NOS teaching can bring to that goal. We view SJ as a vision crucial for acting against inequality, injustice, environmental destruction, marginalization and hegemony prevalent in today's world, and view education conducive for SJ as being integral for achieving such a vision. Having said this we acknowledge that (science) education for SJ is a political choice. As is the case with NOS, the authors in this volume use different SJ frameworks as their starting point. They also emphasize different aspects of SJ in their chapters. We consider those different conceptualizations and emphases crucial for the dialogue and exploration that this volume aims to achieve. 
We argue that if (science) education conducive to SJ is prioritized then NOS teaching and learning cannot stay away from achieving a similar vision.

In this volume, we aim to explore what NOS for SJ could mean, how NOS teaching can contribute to SJ aims, and what NOS content and teaching methods are appropriate when addressing NOS for SJ. Thus, we attempt to bring NOS and SJ agendas closer to each other with the purpose of shedding light on how they can contribute to one another. In particular, we argue for the need to explore: Why should school science aimed at SJ address NOS? What NOS-related content, skills and attitudes form the basis when aiming at SJ? How can school science address NOS for SJ? Related to all of these three questions is the issue of inclusion. Highlighting this perspective in relation to the three questions, we acknowledge that even though the science curriculum and NOS in school science are (in principle) for everyone, they can have the tendency to marginalize and exclude certain groups of students. Therefore, inclusion should be in the foreground when addressing the three questions.

In this introduction chapter, we provide our perspective as editors and initiate a discussion on what NOS for SJ can mean, and what should characterize NOS teaching. It is worth noting that we do not intend to make grandiose claims about what NOS for SJ entails, as it is too early to derive such generalizations. Instead, together with the authors of this volume, we take a humble step and aim to highlight a theme that we believe is important. We also initiate a research-based dialogue on the topic, hoping that the science education community can take it from here, continue the discussion, further refine the construct of NOS for SJ, and develop a solid repertoire of what it entails. At the end of the chapter we provide an overview of the volume and identify some of the main arguments that the authors make as they embark upon this dialogue.

\subsection{Nature of Science (NOS)}

Many science education researchers and a number of science education policy and curriculum documents around the world highlight the importance of NOS teaching and learning (e.g., Hodson 2014). There are different conceptualizations of NOS (e.g., Allchin 2017; Erduran and Dagher 2014; Hodson 2008; Kampourakis 2016; Lederman 2007; Matthews 2012; McComas 2017). Some of these conceptualizations include general tenets, which are thought to be valid across different science disciplines and on which there is some consensus among scholars in philosophy, sociology and the history of science as well as in science education (e.g., Lederman 2007; McComas 2017). Others argue for the need of contextualization and broader perspectives on NOS (Allchin 2011), or describe NOS through different features that are unique or can be shared over different science disciplines (Erduran and Dagher 2014; Matthews 2012).

These various conceptualizations mirror differences with respect to what NOS content is viewed appropriate, possible and/or important to teach in compulsory 
schooling. They also mirror disagreements on NOS among philosophers, sociologists and historians of science, as well as among scientists. As discussed above, conceptualizations of NOS are dependent upon the emphasis given to different historical, philosophical and sociological perspectives, as well as different visions for school science. Thus, NOS could be viewed as a boundary object (Star and Griesimer 1989) in the sense that even though there is agreement among NOS scholars on the importance of including NOS in the teaching of science, there is disagreement regarding the reasons as to why this is important, what NOS perspectives should be taught, and how this should be done. From this standpoint, different reasons are provided in the literature for the inclusion of NOS perspectives in school science (Lederman 2007; Matthews 1994). The reasons include teaching NOS for its own sake to give students the opportunity to learn more nuanced images of science, but also as a means to reach other goals. These goals are related to different visions of scientific literacy (Roberts 2007; Sjöström and Eilks 2018). Frequently mentioned goals include NOS contributing to conceptual understanding, fostering increased interest in science, and teaching science for citizenship.

Part of the NOS literature is concerned with the broadening and problematizing of traditional, stereotypical images of science and scientists frequently communicated in the teaching of science, in textbooks and in the media (e.g., Allchin 2013; McComas 1998). Stereotypical images include scientists being pictured as white men, working alone in laboratory, wearing a lab coat and glasses, and sometimes pictured as the mad genius or at other times more like a superhero (e.g., Chambers 1983; Sjøberg 2000). In addition, stereotypical images of science are communicated both explicitly-for example, as part of a positivistic way to view scientific knowledge and knowledge production-and implicitly. For example, teaching science as a large number of facts may implicitly communicate that scientific knowledge is not open to change. Neither does the "fact tradition" (Zacharia and Barton 2004) of science teaching communicate the processes that has led to these "facts". Accordingly, humans involved in the making of these facts often remain hidden. Another example is that usually neither limits of science nor other ways of knowing are discussed in science classrooms. This results in students frequently associating science with scientism (Hansson and Lindahl 2010). These kinds of stereotypical images of science are communicated in science classrooms even though such views are not part of formal curricula. Instead, they constitute a hidden curriculum in many science classrooms around the world (Hansson 2018). There is a need for understanding what NOS content and teaching approaches can break the reproduction of this hidden curriculum.

Other reasons over why NOS should be part of compulsory science education include developing students' conceptual learning, increasing their interest in science, and fostering the preparation of active citizens. Thus, NOS is viewed as contributing very different visions and overall aims for science teaching, ranging from cultivating future scientists and engineers-what Aikenhead (2006) calls a pipeline science teaching - to fostering activism and SJ. However, with some exceptions (such as Kolstø 2001), NOS literature fails to elaborate on the consequences of these different visions and aims. In line with this, Hodson (2014) argues that "[t]here 
are numerous goals for science education (and education in general) that can, will and should impact on decisions about the NOS content of lessons" (p. 945). Thus, there is a need to scrutinize NOS content, but also teaching approaches with different specific aims for the teaching of science in mind. In this volume, we focus on the goal of SJ and explore what NOS content should be taught, as well as how and why.

\subsection{Social Justice (SJ)}

There is a large body of research related to issues of SJ in general education literature (such as Bell 2016; Zajda et al. 2006). Most often, scholars advocating an education for SJ acknowledge injustices in society and school. They also acknowledge failures to address the marginalization of different student groups based on gender, race, and sexuality, as well as cultural, social and economic background. These scholars often address issues about access, power and equity. Through their recommendations, they hope to achieve some change. Not only in academic literature, but also curricula and other policy documents from different parts of the world focus on SJ in their visions. For example, UN states that "the pursuit of social justice for all is at the core of our global mission to promote development and human dignity" (https://www.un.org/en/events/socialjusticeday/). Working towards an education for SJ means taking a critical stance in relation to different aims of education and the means for achieving those aims. In line with Bell (2016), we highlight the importance of equal participation for all groups in society, equitable distribution of resources, and the need for social actors who have a sense of their own agency and are socially responsible. In addition, in line with Carlisle et al. (2006), we acknowledge the importance of critical perspectives and social action.

Aligned with such a conceptualization of SJ, Keddie (2012) emphasizes a commitment to "the emancipatory possibilities of education" (p. 12) and describes how educators have to work "against the grain of the discourses that impede marginalised students' schooling success" (p. 4). Another example from general education literature is Hackman (2005), who argues that "[t]o be most effective, social justice education requires an examination of systems of power and oppression combined with a prolonged emphasis on social change and student agency in and outside of the classroom" (p. 104). The notion of oppression builds upon Freire's (1970) thoughts; he argues for an education aimed at transforming society by empowering students to take action against oppression. The movement of critical pedagogy, based on Freire's work, is grounded on a vision of SJ and equity. Founded on critical theory, critical pedagogy is dedicated to the alleviation of human suffering and acknowledges that education is political (Kincheloe 2008).

In recent years, more scholars have explored and argued for goals of school science directly related to SJ. There are a number of scholarly books dealing with science education and SJ. Examples include Activist Science and Technology Education by Bencze and Alsop (2014) and Multicultural Science Education: Preparing Teachers for Equity and Social Justice by Atwater et al. (2014). Special issues of 
academic journals targeting SJ in science education have also been developed. Among those are "Teaching and Learning Science for Social Justice" in Equity and Excellence in Education by Barton and Upadhyay (2010) and "Rethinking Education for Citizenship" in the Canadian Journal of Science, Mathematics and Technology Education by Yacoubian and Bazzul (2015).

As in general education literature, $\mathrm{SJ}$ in science education literature is conceptualized in different ways and scholars have emphasized different aspects of it. For example, Butler et al. (2014), in the introduction to the volume Multicultural Science Education: Preparing Teachers for Equity and Social Justice, state that "[c] hallenging the status quo in how science has been traditionally taught is the first step in changing the outcomes of "who does science" (p. 3). This can serve as an example of how science education can contribute in the processes towards SJ by opening up science for more student groups than has traditionally been the case. Along the same lines, Brickhouse and Kittleson (2006) argue for a re-visioning of both science and science education:

\footnotetext{
We envision a science that is responsible for supporting the interests, goals, and needs of a diverse population. /.../ To achieve this kind of science, educators must provide a critical education in science to everyone so that these science related communities are inclusive of everyone, particularly those who have historically benefited least from science. This critical education includes an education in the substance of science, but also in its epistemologies and social relations (p. 204).
}

Other examples include studies focused on possibilities and challenges for different groups in relation to science education, and yet others argue for the need to empower students to be prepared to act in society, and conditions for different social and cultural groups with respect to the teaching and learning of science. For example, using a Freirean perspective, Santos (2009) discusses critical pedagogy, its aim of changing society and its implications for science teaching. Hodson (2011) argues for educating students to become citizens able to engage in sociopolitical activism. Along similar lines, Bencze et al. (2018) argue for science teaching aimed at ecojustice and activism, while Barton and Yang (2000) discuss "cultural power" in relation to science education with the starting point in an ethnographic case study of a homeless, inner-city family.

A number of scholars have explored curricular ideas and contexts in which SJ as an aim can be included in science teaching. Examples include Reiss (2003), who suggests including issues about food, nuclear power and individual differences in teaching units; and Dimick (2012), who uses SJ in an environmental science class. Aikenhead and Michell (2011) elaborate on what a science curriculum recognizing indigenous knowledge could look like, while Bencze (2017) describes an instructional framework - STEPWISE - to be used when teaching for action in relation to controversial, societal and environmental issues. In addition, certain science educators call for having SJ as the guiding framework of science teacher education (e.g., Finkel, 2018). Examples include Atwater et al. (2014), who discuss and provide examples on how to prepare teachers to teach for marginalized student groups. Similarly, Varelas et al. (2018) report on an empirical research involving programmes that equip science teachers with justice-oriented pedagogy. In addition, 
science educators refer to different teaching approaches that can facilitate SJ. Among those approaches are culturally responsive science teaching (Hernandez et al. 2013), justice centred science pedagogy (Morales-Doyle 2018), transformative science education (Codrington 2014), and science education as a means for fostering student ownership (O'Neill 2010).

It is worth noting that $\mathrm{SJ}$ as an overarching aim might include slightly different foci in relation to the teaching of science. These include scrutinizing issues of access and equity within the teaching of science, problematizing perspectives on science itself in the teaching of science, and empowering students to use science as a tool when taking action in relation to societal issues. The latter could have different political/ideological starting points as long as it includes a vision of SJ (see above and Zajda et al. (2006) for a description of how SJ has been connected to different political views).

In summary, in recent years $\mathrm{SJ}$ has been discussed more frequently as an aim of education, in general, and of science education, in particular. There are multiple visions of SJ among science education researchers, which also give rise to divergent research agendas. There is a growing number of studies exemplifying content and teaching approaches in science education aiming for SJ. However, the precise consequences for content and teaching approaches are in need of further scrutiny. In the section that follows, we look more closely into one particular area of science education-NOS teaching - and explore its role and characteristics in school science aimed towards facilitating SJ.

\subsection{NOS for SJ}

This volume aims to explore the relevance of NOS in school science for SJ and outline the consequences that SJ could have on NOS research and practice. We aim to generate a dialogue on the characteristics of NOS teaching for SJ through bringing together a group of scholars, each having different starting points. The dialogue focuses on the three key questions presented earlier: Why should school science aimed at SJ address NOS? What NOS-related content, skills and attitudes form the basis when aimed towards SJ? How can school science address NOS for SJ? The contributors to this dialogue use different approaches and focus on partly different themes, but in one way or another they all contribute with answers and issues related to these questions.

Consequently, NOS and SJ research both contribute to the development of research-based answers to the three key questions. Considering that the questions Why? What? How? are important to frame discussions related to the characteristics of a curriculum (e.g., Dillon 2009; Duit 2015), a research-based dialogue focusing on them could have the potential of contributing towards a curriculum of NOS for $S J$. Figure 1.1 shows a proposed model of how we conceptualize this dialogue. The arrows in the figure are bidirectional to emphasize that NOS research and SJ research both contribute to one another and to the generation of possible answers, 


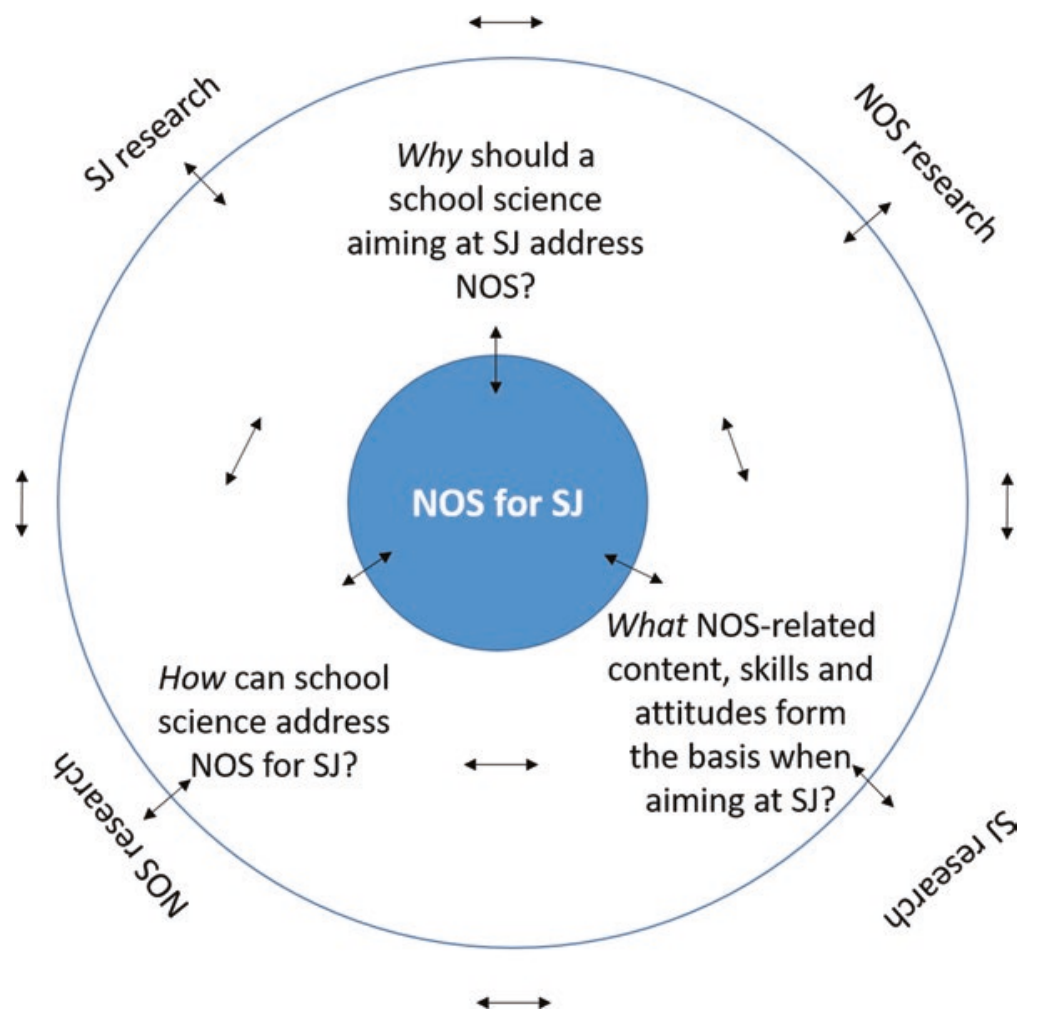

Fig. 1.1 Proposed model for conceptualizing the dialogue in this volume

suggestions and new questions related to the three overall questions, thus contributing to conceptualizing NOS for SJ. These answers, suggestions and new questions all contribute to NOS and SJ research areas. The arrows in between the three questions indicate that the questions are interdependent rather than being independent.

The rest of this introduction chapter aims to initiate a dialogue and illustrate the need to further explore the three questions. Based on relevant literature, we expand on three overarching aims of NOS that we believe are central to developing a rationale for NOS for SJ. These aims could be considered some possible answers to the why question in Fig. 1.1. They are (1) NOS contributing to problematizing notions of science and conceptualizations of NOS, (2) NOS contributing to challenging who science and science education are for (the issue of access), and (3) NOS contributing to empowering students in society. We do not claim that these three aims are the only ones. In addition, we acknowledge that separating them here is purely an analytical choice. In fact, they are intertwined and when considered together have the potential to challenge taken-for-granted answers to the three questions, as well as suggest possibilities of new questions and answers. This is partly because the three aims complement each other but also because they can be viewed as educational means for another educational end (education for social justice). There is certainly 
a need to continue exploring these aims separately. However, there is also a need to study their synergistic effect, as the latter has the potential to contribute with a rich research base to the agenda of NOS for SJ. In the following sections, we illustrate how present lines of NOS and SJ literature can contribute to begin answering the three questions and raising further questions related to the characteristics of NOS for $S J$. We also argue for the need to continue exploring the three questions along different lines of research.

\subsubsection{NOS Contributing to Problematizing Notions of Science and Conceptualizations of NOS}

SJ literature highlights the necessity to problematize the power and special status that science has in society (and school), and how different people are positioned in relation to science. The issue of whose science and NOS are pictured in science teaching are of relevance, as well as how traditional and unproblematized precedencies to specific philosophical and ideological perspectives can be challenged. NOS research can shed some light on how notions of science that are frequently communicated in the science classroom can be problematized, challenged and broadened in the teaching of science. SJ research could contribute to NOS research with respect to providing directions through which to problematize notions of science within the teaching of science. This could contribute to re-evaluating the goals, content and approaches for NOS teaching.

For example, research has shown that even though there are different perspectives on NOS, science classrooms most often and implicitly communicate a narrow span of worldviews and NOS perspectives (Proper et al. 1988; Hansson 2018). For example, positivistic viewpoints are often reproduced in science classrooms around the world. Zacharia and Barton (2004) state that traditional school science is coupled with positivism where "scientific knowledge is an objective representation of how the world works" (p. 203). In line with a SJ agenda, NOS research problematizes and challenges the notion of science as being objective and value free, and instead positions science as a human activity that is embedded in cultural and societal structures, traditions and values. In doing so, many science educators have challenged and suggested alternatives to the positivistic views frequently communicated in the science classroom. Examples include Lederman (2007), who has offered a list of NOS ideas (tenets), Allchin (2013), who has acknowledged the role of culture on scientific claims, and Dagher and Erduran (2016), who have considered the importance of social and cultural values as well as political power structures in shaping scientific knowledge. As discussed earlier, it is worth reminding here that science education researchers also debate consequences of the philosophical discourse on the role of contextual values in science, including issues of reliability and objectivity.

Along the same lines, most often only a narrow span of perspectives is offered in the science classroom with respect to diverse worldviews and ideologies (Hansson 2018). This has been given less attention by NOS researchers, with the exception of those engaged in exploring the relationship between science and religion. One 
example of such a narrow span of perspectives is the frequent communication of scientism in science teaching (Taber 2013), with the consequence that students come to associate science with scientism (Hansson and Lindahl 2010). It is possible to combine scientism with science, but there are many other worldviews (including many religious ones) that are also possible to combine with science. However the latter is often not communicated to students. NOS researchers have argued for the necessity to include the limits of science as part of NOS teaching (McComas 2020; Hansson 2020).

In addition, scholarly literature has highlighted how indigenous knowledge about nature is marginalized in traditional school science. The relation between indigenous knowledge and science is an important area of research in science studies and science education. Debate on the role of culture in science and science education is a contentious area, which derives from competing positions that scholars have regarding NOS. The different positions range from situating culture and its role outside epistemic grounds (e.g., Matthews 1994; Siegel 1997), to arguing for multicultural science (e.g., Snively and Corsiglia 2001) and thus encouraging crosscultural perspectives (Lee et al. 2012), and building decolonizing bridges (e.g., Aikenhead and Ogawa 2007) between western science and indigenous knowledge.

From another perspective, research on ideologies in science education shows that neoliberal perspectives are frequently communicated in science education (e.g. Bencze and Carter 2011). Selby (2014) indicated how science teaching tends to communicate "ever upward progress" and "technological fix" (p. 172). Along similar lines, Yacoubian (2018) showed how different science curriculum and policy documents highlight the importance of scientific literacy through a neoliberal lens, ensuring that developing future citizens' abilities of decision making serve specific neoliberal agendas. There is still need for research to scrutinize how to handle relationships between science and ideology in the teaching of science.

NOS research has focused on problematizing and providing suggestions on how this narrow span of notions of science and conceptualizations of NOS might be addressed in the science classroom. However, more research is needed. In order for NOS to increase its relevance from a SJ perspective, we argue that NOS scholars can challenge themselves, being inspired by SJ literature but also from research in science studies to further problematize their conceptualizations of NOS. For example, looking at today's science teaching: Whose NOS perspectives are being taught? What social and political structures contribute to strengthening rather than challenging stereotypical images and power structures? And scrutinizing the NOS research itself: What needs to be added, changed, and removed from present suggestions of NOS perspectives that should be taught in school? SJ literature sheds light on different perspectives and why some (rather than others) are reproduced in the teaching of science. This is highly relevant for NOS research. In addition, issues such as the kind of NOS curriculum that we are aiming for becomes relevant: Should positivism be replaced with other small-span views of NOS, or should pluralism be the target with respect to NOS perspectives in the science classroom? What are the opportunities and constrains of different alternatives from a SJ perspective? How could these perspectives of NOS be taught in relation to different student groups? 


\subsubsection{NOS Contributing to Challenging Who Science and Science Education Are for (The Issue of Access)}

SJ literature has shown that groups, such as students of colour and female students, continue to be marginalized at schools and in science classrooms. There are many and complex reasons for marginalization. We focus here on one aspect: how does providing distorted images of science and scientists in the teaching of science facilitate the reproduction of inclusion and exclusion patterns in relation to both science teaching and science?

Science textbooks portray stereotypical images of scientists-picturing scientists mostly as male and from Western countries (Vesterinen et al. 2013; Yacoubian et al. 2017). Such stereotypical images are problematic in terms of the implicit messages given to learners regarding who a scientist is and for whom science is designed. Research also shows that both students (Sjøberg 2000; Villar and Guppy 2015) and science teachers (McDuffie 2001) frequently have stereotypical images of scientists.

However, it is not only the images of scientists but also those of science communicated in schools which are highly relevant for the issue of access and the current marginalization of student groups. Science studies research fields have shed light on various perspectives and ways to understand science, but as discussed previously this is rarely communicated to students. This has consequences for student groups who are unable to identify with science in the ways it is presented. For example, students who do not identify with positivistic and scientistic notions of science may have a hard time identifying the relevance of science to them (Hansson and Lindahl 2010). Communicating a very narrow span of NOS perspectives in the teaching of science (including worldview and ideology, such as modernism, technological optimism and neoliberalism) limits the possibilities for students to engage in science in ways meaningful for them. Not providing a broader span of views about science has the consequence that science becomes distorted for many students.

NOS teaching can contribute to a more inclusive school science if it shows students diverse views of how science works rather than prioritizing one view over another. For example, Stenmark (2004) states that it is important to pay attention to what values and what worldviews are present in different phases of scientific research, and which ones are absent. Consequently, he argues that it is essential to provide students with examples of people with different ideologies and worldviews who are actively engaged in scientific research. Thus, if we want to increase the possibilities for students to identify more with science and scientists, science teaching should show how science can be shaped by, and understood from, various worldviews, ideologies and philosophical perspectives. Similarly, it is important to offer the possibility for students to see that people with different backgrounds, interests, abilities, and personalities might find science meaningful despite any sociocultural structures that have limited and still do limit many groups' access to science.

Thus, we argue that in order to break patterns of reproduction and expand on who science education is for, it is important to study how traditions, values, interests, and habits communicated by the scientific community might exclude students. This is in 
line with what is suggested by Andrée and Hansson (2014). NOS research has the potential to contribute perspectives, as well as ways to challenge and problematize traditions, habits, images and values frequently associated with science and scientists. As described previously, such research is present, yet there is still the need to do more work to help understand the details and how broader perspectives of science could find a way into the science classroom. This line of research can contribute towards challenging oppressive traditions that exclude many young people from science. Research that sheds light on the problems of presenting narrow images and traditions is necessary, yet equally important is research exploring possible teaching approaches that challenges these narrow images and highlights possible ways of supporting teachers. In relation to all of this, SJ highlights new perspectives for NOS researchers such as the value of considering grounds for marginalization other than gender and ethnicity (which are more commonly discussed in relation to marginalization). For example, worldview, ideology, and special needs are other grounds in need of further consideration. Interesting questions to further explore include: How do images of NOS communicated in science classrooms limit access and meaningful engagement in science for different student groups, in different parts of the world? What NOS content and teaching methods could contribute to breaking patterns of marginalization?

\subsubsection{NOS Contributing to Empowering Students in Society}

Over the last few decades, science for citizenship has been increasingly discussed in the science education literature as a goal for science teaching. This goal is in addition to traditional ones such as learning science concepts and models for their own sake or preparing students for the next educational level and science careers. For example, a large body of literature deals with science-technology-society (STS) approaches (e.g., Aikenhead 1986), science-technology-society-environment (STSE) approaches (e.g., Pedretti 2005), and 'socio-scientific issues' (SSI) approaches (e.g. Ratcliffe and Grace 2003; Sadler et al. 2007; Zeidler et al. 2005). Even though there are a variety of aims under SSI teaching (Simonneaux 2014), one frequently mentioned aim is to empower students to make decisions on societal issues. The latter is important from a democratic standpoint (Driver et al. 1996; Yacoubian 2018). The aim of empowering students to make use of their knowledge in and about science is related to some conceptualizations of SJ. For example, there are scholars arguing for science education as a means of preparing students to take action on societal issues in their role as citizens (e.g. Bencze 2017; Bencze and Alsop 2014; Hodson 2011). Along the same lines, Bazzul (2015) argues for rethinking how social and political issues are approached in science classrooms, where consensus and non-activist choices prevail. Discussion on the aims of science teaching echoes ongoing discussions in general education literature. For example, Giroux (2019) states "that education is not just about job training and product 
manufacturing, but also about matters of civic engagement, critical thinking, civic literacy and the capacity for democratic agency, action, and change" (p. 149).

Several scholars have pointed out the high relevance of NOS in science curricula oriented towards societal issues (e.g. Aikenhead 2006; Allchin 2017; Driver et al. 1996; Hodson 2011, 2014; Kolstø 2001; Ryder 2001; Yacoubian 2015). It is argued that knowledge of different aspects of NOS is important to be able to make decisions on socio-scientific issues or to take sociopolitical action. Scientific content relevant to socio-scientific issues is often contemporary and ongoing, rather than being part of established science. NOS knowledge is necessary to be able to understand such things as why scientists do not always agree on interpretations or why they are sometimes accused of being biased. The nature of contemporary science performed in universities, private companies or military organizations, as well as issues about research funding are highly relevant to science curricula oriented towards societal issues. In addition, NOS knowledge helps students understand the limits of science and how science can contribute (and not contribute) to decisions made on socio-scientific issues (Hansson 2020). These are examples of NOS perspectives that might empower students to take part in societal and individual decision making where knowledge of science content and its processes are important.

There are a few examples of scholars suggesting specific NOS issues or teaching approaches for NOS in an SSI/activism-oriented curriculum. One example is Kolst $\varnothing$ (2001), who suggests a framework consisting of content-transcending topics, most of which can be viewed as NOS topics (at least in its broad definition). Another example is Yacoubian (2015), who suggests a framework aimed at guiding citizens to think critically with NOS when engaging in decision making on SSI. However, further in-depth research is needed to continue scrutinizing questions such as What NOS concepts should be given priority in science teaching with the aim of empowering students in relation to societal issues? and What could such teaching look like? Thus, scholars need to move forward from arguing that NOS has an important role, to elaborating on the details of what characterizes NOS teaching that empowers students in relation to societal issues and with SJ as an overall aim.

\subsection{Overview of the Current Volume}

The aim of this chapter has been to initiate a dialogue on NOS for SJ. We started this dialogue by illustrating how previous research contributes to answering the three questions - why, what and how - and thus supplies to an agenda of NOS for SJ. We have also suggested issues in need of further research. In their respective chapters, the authors use a variety of approaches and make different recommendations concerning what NOS for SJ is and what it entails. They suggest answers and propose new questions that in different ways relate to the three overall questions (why, what and how).

The intent of this volume is not to reach agreement. On the contrary, we believe that a diversity of ideas and approaches enrich the dialogue and create a healthy 
pathway towards the agenda of NOS for SJ. Thus, the volume could be regarded as a platform upon which the authors engage in a scholarly discussion on what NOS for SJ can mean, and what issues need to be taken into consideration in future research and practice. Our hope is that the volume will contribute some answers, but also highlight new questions. In the paragraphs that follow, we provide a brief overview of the chapters, leaving it for the reader to engage in critical reading and to draw conclusions.

In Chap. 2, From Nature of Science to Social Justice: The Political Power of Epistemic Lessons, Douglas Allchin defends the conventional epistemic approach to NOS by articulating its relevance when applied to scientific claims that inform the distribution of privilege, profit and power. He critiques current approaches to NOS as being "internalist, idealized and decontextualized", and argues for the importance of societal epistemic dimensions that include resolving issues of expertise and credibility, remedying errors due to cultural bias, coping with scientific uncertainties, and counterbalancing conflicts of interest. Such issues, Allchin argues, are important to achieve SJ.

Zoubeida R. Dagher proposes a vision that brings NOS and SJ approaches closer to each other. In Chap. 3, Balancing the Epistemic and Social Realms of Science to Promote Nature of Science for Social Justice, Dagher argues that holistic NOS frameworks that balance social and epistemic domains of science have higher potential and flexibility for engaging learners in reflection on SJ themes compared to frameworks that focus on epistemic statements. Such holistic frameworks, she continues, can link standard-based science and community-based issues.

In Capitalism, Nature of Science and Science Education: Interrogating and Mitigating Threats to Social Justice (Chap. 4), J. Lawrence Bencze and Lynette C. Carter argue against product-oriented science education, which they claim benefits capitalists and provides an idealized image of science and capitalism. Focusing on the capitalist influences on the fields of science and technology and their adverse effects on SJ and environmental health, the authors provide their vision of a sociallyjust NOS education through narratives of approaches in school science education and science teacher education. They argue for the preparation of critical and actionoriented citizens who can evaluate systems of power as well as contribute to improving situations.

In his chapter Political Entanglement and the Changing Nature of Science (Chap. 5), Jesse Bazzul makes a democratic argument and sets forth a "dissensus view of science" - one that recognizes pluralistic NOS as being indispensable for bringing SJ. He argues for politicizing as well as broadening the scope of questions often raised by the proponents of the consensus view of addressing NOS. His proposed questions enable learners to appreciate Western Modern Science in relation to other disciplines and ways of knowing.

Chapter 6, Does Research on Nature of Science and Social Justice Intersect? Exploring Theoretical and Practical Convergence for Science Education, by Sibel Erduran, Ebru Kaya and Lucy Avraamidou discusses how NOS and NOS instruction can contribute to SJ. Drawing from the work of political philosophers such as Rawls and Miller, the authors show some overlapping themes between SJ 
and NOS. Among those themes are diversity, respect, equity, identity, ethos, opportunity and economic fairness. The authors make recommendations for curriculum and instruction.

In Chap. 7, A Discursive Analysis of Relationships Between Nature of Science and Citizenship Education: The Case of Brazilian Science Textbook Evaluation Policies, Rita Vilanova and Isabel Martins report on the results of a critical discourse analysis of policy documents dealing with textbook evaluation and distribution in Brazil. Being particularly interested in exploring the relationship between NOS and citizenship education, the authors find that even though NOS is treated as a key element in education for citizenship, the focus of NOS is on epistemological dimensions of science rather than on sociopolitical, economic and historical dimensions. The authors find this problematic from a citizenship perspective.

The next chapter (Chap. 8) is written by Cristiano Moura, Iamni Torres Jager and Andreia Guerra. In Teaching About Sciences in/ for the Global South: Lessons from a Case Study in a Brazilian Classroom, the authors argue against a critical use of NOS frameworks derived from the Global North within the context of the Brazilian classroom. Using postcolonial theories and an example from a Brazilian classroom in a women's prison, the authors search for a socially conscious alternative for addressing NOS, which can engage learners with meaningful and contextual learning of NOS. They argue for an approach that is considerate to the asymmetries of power inside knowledge and throughout history, and that is sensitive to the particularities of the Brazilian contexts and that promotes SJ.

The chapter entitled Tapping the Potential of Ubuntu for a Science that Promotes Social Justice and Moral Responsibility (Chap. 9), by Meshach Ogunniyi, highlights the importance of the African philosophy of Ubuntu within the community of scientific practice. Ogunniyi underscores the potential of Ubuntu to promote human virtues such as humanness, communalism, interdependence, equity, SJ, and moral responsibility. He shows how science can shift from what he characterizes as a "weapon of oppression" to being more relevant to the lives of students, particularly focusing on the South African experience.

The chapter Teaching Robust Argumentation Informed by the Nature of Science to Support Social Justice. Experiences from Two Projects in Lower Secondary Schools in Norway (Chap. 10), by Stein Dankert Kolstø, elucidates design principles that can be used to empower students to think critically and to produce evidence-based arguments based on their understandings of NOS. The author then discusses the challenges and successes in guiding students through this process by reporting on the implementation and results of two projects.

In Chap. 11, Social Images of Science and of Scientists, and the Imperative of Science Education for All, Agustin Adúriz-Bravo and Alejandro P. Pujalte argue for teaching NOS using a more democratic conception of NOS as well as addressing the social image of science and scientists in a critical way. The authors argue that the traditional pedagogies of science classrooms hinder the possibility of engaging in explicit reflective discussions on NOS. This results in the students forming stereotypes about science and scientists. It also inhibits empowering students and aiming for SJ. 
In the next chapter, Chap. 12, entitled Images of Scientists in Textbooks Aimed at Students in Need of Supplemental Support - An Analysis of Adjustments, Lena Hansson and Lotta Leden report on an analysis of Swedish science textbooks that are adjusted for students who require supplemental support. Using content analysis, the authors compare images of scientists in general textbooks to those found in adjusted ones. The results point to a number of different kinds of adjustments, and Hansson and Leden show how the images of scientists, in different ways, are narrowed in the adjusted textbooks. The authors discuss the different adjustments from a SJ perspective.

Hagop A. Yacoubian in Chap. 13, entitled Turning Unwanted Stereotypes about Scientists into Nature of Science Learning Experiences that Foster Social Justice, argues for a proactive approach in dealing with stereotypes about science and scientists. He suggests the use of stereotypes as resources for teaching and learning in ways that empower learners to critically challenge them. A corrective approach that aims to decrease unwanted stereotypes or expose learners to counter-stereotypes facilitates the goal of SJ. Yet, Yacoubian discusses why those efforts need to be supplemented with a proactive approach, and how the latter facilitates SJ not only as a goal but also as a process.

\section{References}

Aikenhead, G. (1986). The content of STS education. STS Research Network Missive, 2(3), 18-23. Aikenhead, G. S. (2006). Science education for everyday life: Evidence-based practice. New York: Teachers College Press.

Aikenhead, G., \& Michell, H. (2011). Bridging cultures: Indigenous and scientific ways of knowing nature. Ontario: Pearson Education.

Aikenhead, G. S., \& Ogawa, M. (2007). Indigenous knowledge and science revisited. Cultural Studies of Science Education, 2, 539-620. https://doi.org/10.1007/s11422-007-9067-8.

Allchin, D. (2003). Scientific myth-conceptions. Science Education, 87(3), 329-351.

Allchin, D. (2011). Evaluating knowledge of the nature of (whole) science. Science Education, 95(3), 518-542.

Allchin, D. (2013). Teaching the nature of science. Perspectives and Resources. St. Paul: SHiPS Education Press.

Allchin, D. (2017). Beyond the consensus view: Whole science. Canadian Journal of Science, Mathematics and Technology Education, 17(1), 18-26.

Andrée, M., \& Hansson, L. (2014). Recruitment campaigns as a tool for social and cultural reproduction of scientific communities: A case study on how scientists invite young people to science. International Journal of Science Education, 36(12), 1985-2008.

Atwater, M. M., Russell, M., \& Butler, M. B. (Eds.). (2014). Multicultural science education: Preparing teachers for equity and social justice. Dordrecht: Springer.

Barton, A. C. (2003). Teaching science for social justice. New York: Teachers College Press.

Barton, A. C., \& Upadhyay, B. (Eds.). (2010). Teaching and Learning Science for Social Justice (special issue). Equity and Excellence in Education, 43(1).

Barton, A. C., \& Yang, K. (2000). The culture of power and science education: Learning from Miguel. Journal of Research in Science Teaching, 37(8), 871-889. 
Bazzul, J. (2015). Towards a politicized notion of citizenship for science education: Engaging the social through dissensus. Canadian Journal of Science, Mathematics and Technology Education, 15(3), 221-233.

Bell, L. A. (2016). Theoretical foundations for social justice education. In M. Adams, L. A. Bell, D. J. Goodman, \& K. Y. Joshi (Eds.), Teaching for diversity and social justice (3rd ed., pp. 3-26). New York: Routledge.

Bencze, L. (Ed.). (2017). Science and technology education promoting wellbeing for individuals, societies and environments: STEPWISE (Vol. 14). Cham: Springer.

Bencze, J. L., \& Alsop (Eds.). (2014). Activist science and technology education. Dordrecht: Springer.

Bencze, L., \& Carter, L. (2011). Globalizing students acting for the common good. Journal of Research in Science Teaching, 48(6), 648-669.

Bencze, L., Reiss, M. J., Sharma, A., \& Weinstein, M. (2018). STEM education as "Trojan horse": Deconstructed and reinvented for all. In L. Bryan \& K. Tobin (Eds.), 13 Questions: Reframing education's conversation: Science (pp. 69-87). New York: Peter Lang.

Brickhouse, N. W., \& Kittleson, J. M. (2006). Visions of curriculum, community, and science. Educational Theory, 56(2), 191-204.

Butler, M. B., Atwater, M. M., \& Russell, M. L. (2014). Introduction: Culture, equity, and social justice for science teacher educators. In M. M. Atwater, M. Russell, \& M. B. Butler (Eds.), Multicultural science education (pp. 1-7). Dordrecht: Springer.

Carlisle, L. R., Jackson, B. W., \& George, A. (2006). Principles of social justice education: The social justice education in schools. Project, Equity \& Excellence in Education, 39(1), 55-64.

Chambers, D. W. (1983). Stereotypic images of the scientist: The draw-a-scientist test. Science Education, 67(2), 255-265.

Codrington, J. (2014). Sharpening the lens of culturally responsive science teaching: A call for liberatory education for oppressed student groups. Cultural Studies of Science Education, 9(4), 1015-1024. https://doi.org/10.1007/s11422-013-9543-2.

Curd, M., Cover, J. A., \& Pincock, C. (2013). Philosophy of science: The central issues (2nd ed.). New York: W.W. Norton.

Dagher, Z. R., \& Erduran, S. (2016). Reconceptualizing the nature of science for science education: Why does it matter? Science \& Education, 25(1-2), 147-164.

Dillon, J. T. (2009). The questions of curriculum. Journal of Curriculum Studies, 41(3), 343-359.

Dimick, A. S. (2012). Student empowerment in an environmental science classroom: Toward a framework for social justice science education. Science Education, 96(6), 990-1012. https:// doi.org/10.1002/sce.21035.

Driver, R., Leach, J., Millar, R., \& Scott, P. (1996). Young people's images of science. Philadelphia: Open University Press.

Duit, R. (2015). Didaktik. In R. Gunstone (Ed.), Encyclopedia of science education (pp. 325-327). Dordrecht: Springer.

Erduran, S., \& Dagher, Z. (2014). Reconceptualizing the nature of science for science education: Scientific knowledge, practices and other family categories. Dordrecht: Springer.

Finkel, L. (2018). Infusing social justice into the science classroom: Building a social justice movement in science education. The Journal of Educational Foundations, 31(1-2), 38-56.

Freire, P. (1970). Pedagogy of the oppressed. New York: Bloomsbury Publishing.

Giroux, H. (2019). Toward a pedagogy of educated hope under casino capitalism. Pedagogía y Saberes, 50, 147-151.

Hackman, H. W. (2005). Five essential components for social justice education. Equity \& Excellence in Education, 38(2), 103-109.

Hansson, L. (2018). Science education, indoctrination, and the hidden curriculum. In M. R. Matthews (Ed.), History, philosophy and science teaching (pp. 283-306). Cham: Springer.

Hansson, L. (2020). Teaching the limits of science with card sorting activities. In W. F. McComas (Ed.), Nature of science in science instruction: Rationales and strategies. Cham: Springer. 
Hansson, L., \& Lindahl, B. (2010). I have chosen another way of thinking. Science \& Education, 19(9), 895-918.

Hernandez, C. M., Morales, A. R., \& Shroyer, M. G. (2013). The development of a model of culturally responsive science and mathematics teaching. Cultural Studies of Science Education, $8(4), 803-820$.

Hodson, D. (2008). Towards scientific literacy: A teachers' guide to the history, philosophy and sociology of science. Rotterdam: Sense Publishers.

Hodson, D. (2011). Looking to the future. Building a curriculum for social activism. Rotterdam: Sense Publishers.

Hodson, D. (2014). Nature of science in the science curriculum: Origin, development, implications and shifting emphases. In M. R. Matthews (Ed.), International handbook of research in history, philosophy and science teaching (pp. 911-970). Dordrecht: Springer.

Jost, J. T., \& Kay, A. C. (2010). Social justice: History, theory, and research. In S. T. Fiske, D. T. Gilbert, \& G. Lindzey (Eds.), Handbook of social psychology (pp. 1122-1165). Hoboken: Wiley.

Kampourakis, K. (2016). The "general aspects" conceptualization as a pragmatic and effective means to introducing students to nature of science. Journal of Research in Science Teaching, 53(5), 667-682.

Keddie, A. (2012). Educating for diversity and social justice. New York: Routledge.

Kincheloe, J. (2008). Critical pedagogy primer. New York: Peter Lang.

Kolst $\varnothing$, S. D. (2001). Scientific literacy for citizenship: Tools for dealing with the science dimension of controversial socioscientific issues. Science Education, 85(3), 291-310.

Leden, L., Hansson, L., \& Redfors, A. (2017). From black and white to shades of grey. Science \& Education, 26(5), 483-511.

Lederman, N. G. (2007). Nature of science: Past, present, and future. In S. K. Abell \& N. G. Lederman (Eds.), Handbook of research on science education (pp. 831-879). Mahwah: Lawrence Erlbaum Associates.

Lee, H., Yen, C.-F., \& Aikenhead, G. S. (2012). Indigenous elementary students' science instruction in Taiwan: Indigenous knowledge and western science. Research in Science Education, 42, 1183-1199. https://doi.org/10.1007/s11165-011-9240-7.

Longino, H. E. (1990). Science as social knowledge: Values and objectivity in scientific inquiry. Princeton: Princeton University Press.

Matthews, M. R. (1994). Science teaching: The role of history and philosophy of science. New York: Routledge.

Matthews, M. R. (2012). Changing the focus: From nature of science (NOS) to features of science (FOS). In M. S. Khine (Ed.), Advances in nature of science research (pp. 3-26). Dordrecht: Springer.

McComas, W. F. (1998). The principal elements of the nature of science: Dispelling the myths. In W. F. McComas (Ed.), The nature of science in science education: Rationales and strategies (pp. 53-70). Dordrecht: Kluwer Academic.

McComas, W. F. (2017). Understanding how science works: The nature of science as the foundation for science teaching and learning. School Science Review, 98(365), 71-76.

McComas, W. F. (2020). Nature of science in science instruction: Rationales and strategies. Cham: Springer.

McDuffie, T. E. (2001). Scientists - Geeks and nerds? Science and Children, 38(8), 16-19.

Morales-Doyle, D. (2018). Students as curriculum critics: Standpoints with respect to relevance, goals, and science. Journal of Research in Science Teaching, 55(5), 749-773.

O'Neill, T. B. (2010). Fostering spaces of student ownership in middle school science. Equity \& Excellence in Education, 43(1), 6-20.

Pedretti, E. (2005). STSE education: Principles and practices. In S. Alsop, L. Bencze, \& E. P. Pedretti (Eds.), Analysing exemplary science teaching: Theoretical lenses and a spectrum of possibilities for practice (pp. 116-126). London: Open University Press. 
Pérez-Garzón, C. A. (2018). Unveiling the meaning of social justice in Colombia. Mexican Law Review, 10(2), 27-66.

Proper, H., Wideen, M. F., \& Ivany, G. (1988). World view projected by science teachers: A study of classroom dialogue. Science Education, 72(5), 547-560.

Ratcliffe, M., \& Grace, M. (2003). Science education for citizenship: Teaching socio-scientific issues. London: McGraw-Hill Education.

Reiss, M. J. (2003). Science education for social justice. In C. Vincent (Ed.), Social justice, education and identity (pp. 163-174). London: Routledge Falmer.

Roberts, D. A. (2007). Scientific literacy/science literacy. In S. K. Abell \& N. G. Lederman (Eds.), Handbook of research on science education (pp. 729-780). Mahwah: Lawrence Erlbaum Associates.

Rudolph, J. L. (2000). Reconsidering the 'nature of science' as a curriculum component. Journal of Curriculum Studies, 32(3), 403-419. https://doi.org/10.1080/002202700182628.

Ryder, J. (2001). Identifying science understanding for functional scientific literacy. Studies in Science Education, 36(1), 1-44. https://doi.org/10.1080/03057260108560166.

Sadler, T. D., Barab, S. A., \& Scott, B. (2007). What do students gain by engaging in socioscientific inquiry? Research in Science Education, 37(4), 371-391.

Santos, W. L. P. (2009). Scientific literacy: A Freirean perspective as a radical view of humanistic science education. Science Education, 93, 361-382.

Selby, D. E. (2014). Education for sustainable contraction as appropriate response to global heating. In L. Bencze \& S. Alsop (Eds.), Activist science and technology education (pp. 165-182). Dordrecht: Springer.

Siegel, H. (1997). Science education: Multicultural and universal. Interchange, 28, 97-108. https:// doi.org/10.1023/A:1007314420384.

Simonneaux, L. (2014). From promoting the techno-sciences to activism - A variety of objectives involved in the teaching of SSIs. In L. Bencze \& S. Alsop (Eds.), Activist science and technology education (pp. 99-111). Dordrecht: Springer.

Sjøberg, S. (2000). Science and scientists: the SAS study. Retrieved April 4, 2005, from http://folk. uio.no/sveinsj/SASweb.htm.

Sjöström, J., \& Eilks, I. (2018). Reconsidering different visions of scientific literacy and science education based on the concept of Bildung. In Y. J. Dori et al. (Eds.), Cognition, metacognition, and culture in STEM education (pp. 65-88). Cham: Springer.

Snively, G., \& Corsiglia, J. (2001). Discovering indigenous science: Implications for science education. Science Education, 85, 6-34. https://doi.org/10.1002/1098-237X(200101)85:13.0.CO ;2-R.

Star, S., \& Griesimer, J. (1989). Institutional ecology, 'Translations' and boundary objects: Amateurs and professionals in Berkeley's Museum of Vertebrate Zoology, 1907-39. Social Studies of Science, 19(3), 387-420.

Stenmark, M. (2004). How to relate science and religion: A multidimensional model. Michigan: W. B. Eerdmans Publishing.

Taber, K. S. (2013). Conceptual frameworks, metaphysical commitments and worldviews: The challenge of reflecting the relationships between science and religion in science education. In N. Mansour \& R. Wegerif (Eds.), Science education for diversity. Theory and practice (pp. 151-177). Dordrecht: Springer.

Varelas, M., Morales-Doyle, D., Raza, S., Segura, D., Canales, K., \& Mitchener, C. (2018). Community organizations' programming and the development of community science teachers. Science Education, 102(1), 60-84.

Vesterinen, V.-M., Aksela, M., \& Lavonen, J. (2013). Quantitative analysis of representations of nature of science in Nordic upper secondary school textbooks using framework of analysis based on philosophy of chemistry. Science \& Education, 22, 1839-1855.

Villar, P., \& Guppy, N. (2015). Gendered science: Representational dynamics in British Columbia science textbooks. Canadian Journal of Education, 38(3), 1-24. 
Yacoubian, H. A. (2015). A framework for guiding future citizens to think critically about nature of science and socioscientific issues. Canadian Journal of Science, Mathematics and Technology Education, 15(3), 248-260.

Yacoubian, H. A. (2018). Scientific literacy for democratic decision-making. International Journal of Science Education, 40(3), 308-327.

Yacoubian, H. A., \& Bazzul, J. (Eds.). (2015). Rethinking education for citizenship [special issue]. Canadian Journal of Science, Mathematics, and Technology Education, 15(3), 211-215.

Yacoubian, H. A., Al-Khatib, L., \& Mardirossian, T. (2017). Analysis of the image of scientists portrayed in the Lebanese national science textbooks. Science \& Education, 26(5), 513-528.

Zacharia, Z., \& Barton, A. C. (2004). Urban middle-school students' attitudes toward a defined science. Science Education, 88(2), 197-222.

Zajda, J., Majhanovich, S., \& Rust, V. (2006). Education and social justice: Issues of liberty and equality in the global culture. In J. Zajda, S. Majhanovich, V. Rust, \& E. M. Sabina (Eds.), Education and social justice (pp. 1-12). Dordrecht: Springer.

Zeidler, D. L., Sadler, T. D., Simmons, M. L., \& Howes, E. V. (2005). Beyond STS: A researchbased framework for socioscientific issues education. Science Education, 89(3), 357-377.

Open Access This chapter is licensed under the terms of the Creative Commons Attribution 4.0 International License (http://creativecommons.org/licenses/by/4.0/), which permits use, sharing, adaptation, distribution and reproduction in any medium or format, as long as you give appropriate credit to the original author(s) and the source, provide a link to the Creative Commons license and indicate if changes were made.

The images or other third party material in this chapter are included in the chapter's Creative Commons license, unless indicated otherwise in a credit line to the material. If material is not included in the chapter's Creative Commons license and your intended use is not permitted by statutory regulation or exceeds the permitted use, you will need to obtain permission directly from the copyright holder.

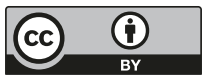

